\title{
Comparison of Intraocular Pressure among Individuals with Systemic Hypertension and those with Normal Blood Pressure
}

\author{
Sanket Parajuli ${ }^{1}{ }^{\circ}$, Pooja Shrestha $^{2}$, Jeevan K Shrestha ${ }^{2}$, Sadhana Sharma ${ }^{3}$ \\ Reiyukai Eiko Masunaga Eye Hospital, Banepa, Nepal \\ ${ }^{2}$ Dhulikhel Hospital, Dhulikhel, Nepal \\ ${ }^{3}$ Mechi Eye Hospital, Birtamode, Jhapa, Nepal
}

\begin{abstract}
Introduction: Systemic blood pressure, by far, is one of the most important factors that can have an effect on intraocular pressure. We have compared the intraocular pressure (IOP) among patients with systemic hypertension and those with normal blood pressure.

Materials and methods: A hospital based case control study was conducted from March 2017 to March 2018 in the Ophthalmology outpatient department at Dhulikhel Hospital. A total of 100 patients with hypertension were included in the case group (hypertensive group) and 100 cases with no systemic or ocular disease were included in the control group (normotensive group). Mean intraocular pressures were calculated and compared between the two groups.
\end{abstract}

Results: Mean age of patients was 49.03 years in hypertensive group and 47.53 years in normotensive group. Mean IOP of the right eye in those with hypertension was $16.10 \mathrm{mmHg}$ and in the left eye was 15.8 $\mathrm{mmHg}$. Similarly mean IOP of the right eye in the normotensive group was $15.8 \mathrm{mmHg}$ and the left eye was $16.2 \mathrm{mmHg}$. The difference between mean IOP of hypertensive and normotensive individuals was not statistically significant $(\mathrm{p}>0.05)$. The prevalence of ocular hypertension was found to be $7.5 \%$.

Conclusion: There was no statistically significant difference in IOP between hypertensive and normotensive individuals. However, a statistically significant difference in IOP was noted between 'hypertensive with controlled blood pressure' and 'hypertensive with uncontrolled BP' indicating that high blood pressure may be associated with high IOP.

Key words: Eye, Hypertension, Intraocular pressure, Ocular hypertension.

Financial Interest : Nil

Conflict of Interest : Nil

Received : 19.12.2020

Accepted : 09.05.2021

Corresponding Author

Dr. Sanket Parajuli

Reiyukai Eiko Masunaga Eye Hospital,

Banepa, Nepal.

E-mail: sanketparajuli@gmail.com
Access this article online

Website: www.nepjol.info/index.php/NEPJOPH

DOI: https://doi.org/10.3126/nepjoph.v13i2.33917

Copyright $\odot 2021$ Nepal Ophthalmic Society ISSN: 2072-6805, E-ISSN: 2091-0320

This work is licensed under a Creative Commons Attribution-NonCommercial-NoDerivatives 4.0 International License (CC BY-NC-ND). 


\section{INTRODUCTION}

Intraocular pressure (IOP) is maintained by the equilibrium in production and drainage of the aqueous humor and normally ranges from 10-21 mm $\mathrm{Hg}$ (mean 16 \pm 2.5 ) (Kasper et al, 2005). Intraocular pressure is affected by various factors such as age, blood pressure and blood sugar level (Levin et al, 2011; Klein et al, 2005). Increased ciliary epithelial sodium transport leading to an excessive aqueous humor formation and subsequent high IOP has been reported in systemic hypertension. Variations in systolic blood pressure also results in small changes in aqueous humour formation as a result of increased capillary pressure in the ciliary body. This indeed could result in increased intraocular pressure (Bill, 1973). Blood pressure also affects episcleral venous pressure, which is important in regulating the flow of aqueous across the trabecular meshwork into Schlemm's canal (Levin et al, 2001).

Intraocular pressure is regarded as the most important modifiable risk factor associated with the development of glaucomatous optic neuropathy (Leske et al, 2001; Le et al, 2003). Population based screening for an elevated intraocular pressure and its control could reduce the number of people who are at the greatest risk of glaucoma (Kisan et al, 2012).

Thus, all the patients with high blood pressure must be investigated for raised intraocular pressure so as to identify glaucoma as early as possible and decrease the morbidity caused by the disease.

\section{MATERIALS AND METHODS}

A hospital based prospective case control study was conducted from March 2017 to March 2018 in the Ophthalmology outpatient department in Dhulikhel hospital. Ethical consideration was taken from the institutional review committee (IRC-KUSMS 86/17). Sample size was calculated using the formula $\mathrm{n}=\mathrm{Z}^{2} * \mathrm{P} *(1-\mathrm{P}) / \mathrm{e}^{2}$, where, $Z=$ constant for $95 \%$ confidence interval, $\mathrm{P}=$ Prevalence of ocular hypertension in people more than 40 years of age, $\mathrm{e}=$ allowable error. Taking $\mathrm{P}=7$ (Leske et al, 1995), $\mathrm{Z}=1.96$ and $\mathrm{e}=5 \%$ sample size calculated was 100 . So, 100 patients with hypertension were included in the case group and 100 cases with no systemic or ocular disease were included in the control group after matching the age and gender with the case group.

Primary objective was to compare the intraocular pressure (IOP) among patients with systemic hypertension and those with normal blood pressure. Secondary objective was to find prevalence of ocular hypertension in patients above 40 years of age. Every $3^{\text {rd }}$ patient of age more than 40 years with diagnosed hypertension, including both the old cases and recently diagnosed cases of hypertension attending the ophthalmology OPD irrespective of the duration of hypertension were included in the study. After matching the age and gender, the 
individuals without hypertension were included in the control group.

Exclusion criteria included age $<40$ years, diabetes mellitus (type 1 or type 2), high myopia or history of glaucoma, ocular pathology which can cause increase in intraocular pressure or glaucomatous changes in optic disc like uveitis, vein occlusions, media opacities like significant cataract, corneal opacity which would hamper posterior segment examination. Those patients who were never found to have high blood pressure and whose blood pressure is $<140 / 90$ $\mathrm{mm} \mathrm{Hg}$ were kept in the normotensive group. Among patients with diagnosed hypertension, those with $\mathrm{BP} \leq 140 / 90 \mathrm{~mm} \mathrm{Hg}$ were kept under hypertensive with controlled BP group whereas those with $\mathrm{BP}>140 / 90 \mathrm{~mm} \mathrm{Hg}$ were kept under hypertensive with uncontrolled BP group.

For every patient, a detailed history was obtained regarding the age, sex, ocular symptoms, duration and treatment of hypertension. Ocular examination included recording of visual acuity with Snellen's chart, retinoscopy, anterior and posterior segment examination with slit lamp biomicroscopy. Measurement of intraocular pressure was carried out by Goldman's applanation tonometer [Haag streit BQ 900]. Mean of 3 readings was taken for every patient. Optic disc evaluation was done on both the eyes of every case and control. The optic disc evaluation included color, shape, size, margin, cup disc ratio, neuroretinal rim, retinal nerve fiber layer loss, peripapillary atrophy and specific signs like bayonetting sign, baring sign or laminar dot sign. For every case with a suspicious disc, visual field examination was done using Humphrey's automated visual field perimetry (Carl Zeiss Meditec AG). For all cases, grading of hypertension was done according to Keith-Wagener-Barker classification (Keith et al, 1939).

For the purpose of our study, we defined Ocular hypertension as those with IOP $>21 \mathrm{~mm} \mathrm{Hg}$ in at least 1 eye without field defects. POAG was diagnosed as patients with suspicious disc $(\mathrm{C}$ : $\mathrm{D}$ ratio $>0.5$ ), open angles on gonioscopy and visual field defects.

Statistical analysis was done using the Statistical Package for the Social Sciences (SPSS) version 25. Mean of IOP of each group was calculated and comparison was carried out using paired t-test.

\section{RESULTS}

In this study a total of 200 patients were included among which 100 were hypertensive patients as diagnosed by the Medicine department of Dhulikhel Hospital and the other 100 were normotensive patients. Mean age of patients were 49.03 in hypertensive group and 47.53 years in Normotensive group. 59 males and 41 females were included in hypertensive group whereas 62 males and 38 females were included in the normotensive group (Table 1). 
飬

NEPiog 


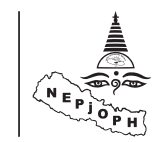


young South African adult population (Sithole et al, 2009).

A statistically significant difference of mean intraocular pressures betweenhypertensives with uncontrolled blood pressure and hypertensives with controlled blood pressure was observed in our study. Statistically significant difference of IOP in relation to blood pressure was also seen in the "Egnaneumarkt study" (Bonomiet al, 2000). Similar results were also seen in the study by Thampi et al (2017) where the mean IOP in the hypertensive group was significantly higher than those without hypertension (Thampi et al, 2017). Kishan et al. conducted a study where blood pressure was positively independently correlated to the IOP (Kisan et al, 2012). A positive association between the systolic BP and a raised IOP has constantly been shown in both cross sectional and longitudinal studies (Klein et al, 1981; McLeod et al, 1990; Rochtchina et al, 2002). Some studies have shown that the diastolic BP was positively associated with a raised IOP (Klein et al, 2005; Hiller et al, 1982). The Los Angeles Latino Eye Study also reported an increase in IOP with increase in blood pressure (Memarzadehet al, 2010).

Prevalence of ocular hypertension in this study population was found to be $7.5 \%$ which is comparable to the prevalence of ocular hypertension in Framingham Eye Study and the Baltimore Eye Survey (Sommer A, 1996; Kahn et al. 1977). The prevalence of POAG in our study was $1.5 \%$.The prevalence of POAG in our study is similar to prevalence in
Bhaktapur glaucoma study where the age and sex standardized prevalence of POAG was $1.24 \%$ (Thapa et al, 2013).

Hypertensive retinopathy was seen in 27 of 100 hypertensive patients. This prevalence of retinopathy is comparable to prevalence seen in other studies (Shantha et al, 2010; Besharati et al, 2006).

\section{CONCLUSION}

There was no statistically significant difference in IOP between hypertensive and normotensive individuals. However, there was a statistically significant difference in IOP between 'hypertensives with controlled BP' and 'hypertensives with uncontrolled BP'.

We recommend that all patients with hypertension must undergo periodic eye examination for early diagnosis of ocular hypertension and POAG.

Limitations: In this study, IOP was taken in only one sitting and the diurnal variation was not taken into account. This may give false results in some patients who may show a normal IOP level at a certain time of the day but may show a larger diurnal variation.

Acknowledgements: Authors would like to acknowledge Dr. Angira Shrestha and Dr. Tina Shrestha for their constant support and encouragement.

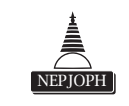




\section{REFERENCES}

Bill A. The role of ciliary body blood flow and ultrafiltration in aqueous humor formation. Exp Eye Res. 1973; 16(4):287-98. doi: 10.1016/0014-4835(73)90094-8

Bonomi L, Marchini G, Marraffa M, Bernardi P, Morbio R, Varotto A. Vascular risk factors for primary open angle glaucoma:theEgna-Neumarkt study. Ophthalmology 2000; 107 (7):1287-93. doi: 10.1016/S0161-6420(00)00138-X

Hiller R, Sperduto RD, Krueger DE. Race, iris pigmentation and intraocular pressure. American Journal of Epidemiology. 1982; 115 (5):674-83. doi: 10.1093/oxfordjournals.aje.a113350; PMid:7081199

Kahn HA, Leibowitz HM, Ganley JP et al. The Framingham Eye Study. II. Association of ophthalmic pathology with single variables previously measured in the Framingham Heart Study. American Journal of Epidemiology. 1977; 106:33- 41. doi: 10.1093/oxfordjournals.aje.a112429; PMid:141882

Kasper DL, Braundwald E, Fauci AS, Hauser SL, Longo DL, Jameson JL. Harrison's Principles of Internal Medicine: Disorders of the eye. 16th edition. United States of America. The McGraw Hill Companies, 2005: 162-75.

Kisan R, Kisan SR, OR A, SP C, Skoujalagi R. Correlation between intraocular Pressure and the Blood Pressure in Different Age Groups. Journal of Clinical and Diagnostic Research. May 2012 6(4):581-85.

Klein BE Klein R, Knudtson MD. Intra-ocular pressure and systemic blood pressure: a longitudinal perspective: the Beaver Dam eye study. British Journal of Ophthalmology. 2005;89 (3):284-87. doi: 10.1136/bjo.2004.048710; PMid:15722304

Le A, Mukesh BN, McCarty CA, Taylor HR. Risk factors associated with the incidence of open - angle glaucoma: the visual impairment project. Invest Ophthalmology Vision Science. September 2003; 44(9):3783-89. doi: 10.1167/ iovs.03-0077; PMid:12939292

Leske MC, Connell AMS, Wu SY, Nemesure B, Li X, Schachar A. Incidence of open-angle glaucoma. Archives of Ophthalmology 2001; 119(1):89-95.

Leske MC, Warheit-Roberts L, Wu SY. Open-angle glaucoma and ocular hypertension: the Long Island Glaucoma Case-control Study. Ophthalmic Epidemiology. 1995; 3: 85-96. doi: 10.3109/09286589609080113; PMid:8841060

Levin A, L Nilsson S. Alder's Physiology of the Eye: production and flow of aqueous humor. 11th edition. London. Elsevier, 2011: 274-307. doi: 10.1016/B978-0-323-05714-1.00011-X

McLeod SD, West SK, Quigley HA, Fozard JL. A longitudinal relationship between intra-ocular and blood pressures. Invest Ophthalmology Vision Science. 1990; 31:2361-66.

Memarzadeh F YLM, Chung J, Azen SP, Varma R Blood pressure, perfusion pressure, and open angle glaucoma: The Los Angeles Latino Eye Study. Invest Ophthalmol Vis Sci 2010; 51. doi: 10.1167/iovs.08-2956; PMid:20089880

Mondal RN, Matin A, Rani M, Hossain Z, Shaha AC, Singh RB, et al. Prevalence and Risk Factors of Hypertensive Retinopathy in Hypertensive Patients. Journal of Hypertension: Open Access. 2017; 6 (2):8-14

Rochtchina E, Mitchell P, Wang JJ. Relationship between age and intra-ocular pressure: the Blue Mountains eye study. Clinical Experiment in Ophthalmology 2002; 30 (3):173-77. doi: 10.1046/j.1442-9071.2002.00519.x; PMid:12010208

Shantha GP, Srinivasan Y, Kumar AA, Salim S, Prabakhar S, Rajan AG et al. Can retinal changes predict coronary artery disease in elderly hypertensive patients presenting with angina? Am J Emerg Med 2010; 28(5):617-21. doi: 10.1016/j.ajem.2009.04.007; PMid:20579560 
Parajuli $S$ et al

IOP comparison in individuals with Systemic Hypertension and Normal Blood Pressure

Nepal J Ophthalmol 2021; Vol 13 (26): 137-44

Sithole H, Arbee T, Nxumalo N, Tshatsha N, Perumal K, Ali ZM, et al. A correlational study of systemic blood pressure and intraocular pressure in a young South African adult population. The South African Optometrist 2009; 68 (4):6-7. doi: 10.4102/aveh.v68i4.176

Sommer A. Glaucoma risk factors observed in the Baltimore Eye Survey. CurrOpinOphthalmol 1996; 7(2):93-8. doi: 10.1097/00055735-199604000-00016; PMid:10163329

Thampi B, Mahadevan K, Rekha R.S, Simi F. Relationship between Intraocular Pressure and Mean Ocular Perfusion Pressure in Hypertensive and Non Hypertensive Adult Population Scholars Journal of Applied Medical Sciences (SJAMS) 2017; 5(8):3313-17

Thapa SS, Poudel I, Khanal S, Van Res G. Results of the Bhaktapur Glaucoma Study. Nepal Journal of Ophthalmology. 2013; 5(1):81-93. doi: 10.3126/nepjoph.v5i1.7832; PMid:23584652 